\title{
Pathergy phenomenon: an important clinical pointer to Behçet disease
}

\author{
Dharmagat Bhattarai, ${ }^{\oplus}$ Pandiarajan Vignesh, Deepti Suri, Anju Gupta
}

Pediatrics, Postgraduate Institute of Medical Education and Research, Chandigarh, India

Correspondence to Dr Pandiarajan Vignesh, vigimmc@gmail.com

Accepted 6 June 2019

\section{DESCRIPTION}

A 5-year-old girl presented with a history of intermittent fever, recurrent aphthous oral ulcers and pustulo-nodular skin lesions spreading with contractures and disfiguring scars at sites of trauma. She had a history of the development of skin lesions at the site of minor trauma, intramuscular injection and intravenous cannulation (figure 1). She had received multiple courses of intravenous and oral antibiotics before referring to our centre for the suspicion of infective aetiology for pustular lesions. Genitalia and eye examinations were unremarkable. The systemic examination was normal.

Investigations showed microcytic hypochromic anaemia (haemoglobin $66 \mathrm{~g} / \mathrm{L}$; mean corpuscular volume $65 \mathrm{fL}$; mean corpuscular haemoglobin $19 \mathrm{pg}$ ), mild neutrophilic leucocytosis (total leucocytes $14.5 \times 10^{9} / \mathrm{L}$ with $70 \%$ neutrophils), thrombocytosis $\left(729 \times 10^{9} / \mathrm{L}\right)$ and elevated erythrocyte sedimentation rate $(63 \mathrm{~mm}$ in the first hour). Blood cultures and swab culture from local sites were sterile. Pathergy test was performed using a blunt hypodermic
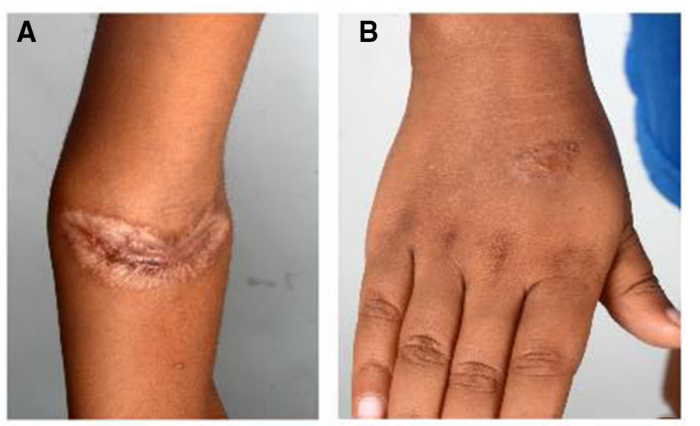

C
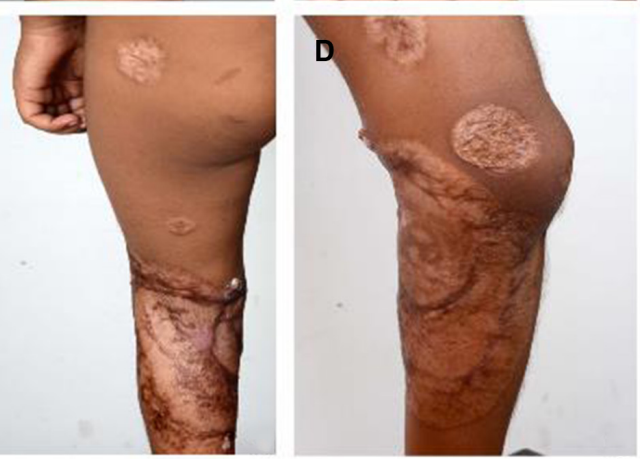

Figure 1 (At the time of initial presentation) Pathergy phenomenon-characteristic scarring skin lesions over right cubital region (A); dorsum of hand at site of insertion of intravenous cannula (B); lesions over left buttock (at intramuscular injection site) and popliteal region (C); and in left calf, and upper leg region (D) following minor trauma.
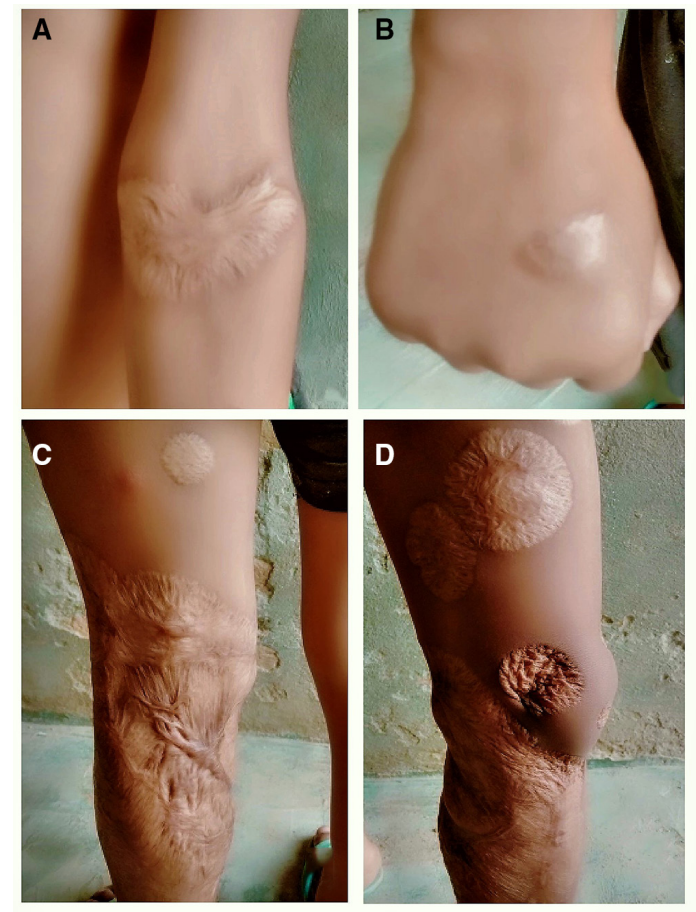

Figure 2 (After 1 year of initial presentation) Healed scars over the right cubital region (A); dorsum of hand at the site of insertion of an intravenous cannula (B); healed scar over the popliteal region (C); and scars in the left calf, and upper leg region (D) after immunosuppressant therapy.

needle by inserting it $3-4 \mathrm{~mm}$ depth at an angle of $30^{\circ}$ at four sites on the middle of the forearm. Pustules were observed at the sites of puncture after 48 hours of prick suggesting a positive test. Skin biopsy showed dermal spongiosis, necrotic folliculitis and neutrophilic infiltrates up to subcutis, suggestive of the morphology of pyoderma gangrenosum (PG) (online supplementary figure). She was positive for HLA B51 by PCR. In view of recurrent oral aphthous ulcers, classic skin lesions and positive pathergy test, a diagnosis of Behçet disease (BD) was made. ${ }^{1}$

As the lesions were extensive and disfiguring, we planned to treat her with long-term immunosuppressive medication such as azathioprine or cyclosporine. ${ }^{23}$ On the basis of available literature for the management of PG-like lesions in BD and after discussion with the parents, she was started on oral cyclosporine $(4 \mathrm{mg} / \mathrm{kg} /$ day $)$ and oral prednisolone $(2 \mathrm{mg} /$ $\mathrm{kg} /$ day) that was later tapered and stopped in next 4 months. The lesions healed gradually and no relapse was noted in the follow-up. After 1-year follow-up, only healed scars were noted (figure 2 ). There was no recurrence of fever and aphthous lesions. 
Pathergy reaction is the phenomenon of formation of non-healing skin lesions or ulcers following minor injuries. The reaction is usually seen in $\mathrm{BD}$, Sweet's syndrome, inflammatory bowel disease, and spondyloarthropathies. ${ }^{4}$ Pathergy phenomena may sometimes present as localised PG-like lesions at the site of minor trauma. ${ }^{5}$ Positive pathergy is regarded as a valuable lead point for the diagnosis of BD in patients with recurrent oral aphthosis and genital, eye or skin lesions. Recently revised International Criteria do not directly include the pathergy test as a criterion, but it is regarded for additional point if it is positive in a suspected case of BD. ${ }^{1}$ The index child had recurrent oral ulcers, skin lesions and positive pathergy reaction contributing adequate diagnostic points in favour of diagnosis of BD. ${ }^{1}$ Moreover, HLAB51 sub-allele is a well-known association in patients with BD though it is not included in diagnostic criteria. The European League against Rheumatism (EULAR) 2018 guidelines state the use of second-line immunosuppressive agents

\section{Patient's perspective}

I am the father of the child. My child had sinister lesions which my doctors have treated well. We are described well about the disease. I give my valid consent for the publication of images of my child.

\section{Learning points}

Pathergy reaction is a phenomenon of development of skin lesions or ulcers following trivial trauma.

- Accidental trauma, surgery incisions, or investigational needle- pricks can trigger the pathergy reaction.

- Pathergy phenomenon is an important clinical clue for underlying Behçet disease. such as azathioprine, anti-TNF $\alpha$ agents, apremilast or thalidomide in cases of severe mucocutaneous lesions in BD. However, these drugs have mainly been used for severe oro-genital ulcers, papulopustular or acne-like lesions in $\mathrm{BD} .^{2}$ There are no clear management guidelines for PG-like ulcerative lesions in BD. Management of such lesions is guided by expert opinion, safety, cost and patients' preferences. ${ }^{2}$ Many anecdotal studies report the successful use of cyclosporine in PG-like lesions in BD. ${ }^{36} \mathrm{We}$ treated the index child with cyclosporine and the child showed a good clinical response.

To conclude, pathergy reaction is a clinical pointer of BD and no paediatrician should miss this important clinical clue.

Contributors DB: conception, planning, conduct, primary drafting, corrections, primary management of the patient. PV: conception, planning, conduct, reporting, conception and design, editing and finalising the draft. DS and AG: acquisition of draft and analysis with the interpretation of findings, patient management, editing.

Funding The authors have not declared a specific grant for this research from any funding agency in the public, commercial, or not-for-profit sectors.

Competing interests None declared.

Patient consent for publication Parental/guardian consent obtained.

Provenance and peer review Not commissioned; externally peer reviewed.

\section{REFERENCES}

1 Davatchi F, Assaad-Khalil S, Calamia KT, et al. The International Criteria for Behçet's Disease (ICBD): a collaborative study of 27 countries on the sensitivity and specificity of the new criteria. J Eur Acad Dermatol Venereol 2014:28:338-47.

2 Hatemi G, Christensen R, Bang D, et al. update of the EULAR recommendations for the management of Behçet's syndrome. Ann Rheum Dis 2018:2018:808-18.

3 Kim DW, Lee BI, Park SH. Accelerated healing of pyoderma gangrenosum in Behçet patient treated with cyclosporine and split thickness skin graft. Ann Plast Surg 2008;61:552-4

4 Sequeira FF, Daryani D. The oral and skin pathergy test. Indian J Dermatol Venereol Leprol 2011;77:526-30.

5 Ozuguz P, Kacar SD, Manav V, et al. Genital Ulcerative Pyoderma Gangrenosum in Behçet's Disease: A Case Report and Review of the Literature. Indian J Dermatol 2015;60:105.

6 Chams-Davatchi C, Shizarpour M, Davatchi F, et al. Extensive pyoderma gangrenosumlike lesion in two cases of Behçet's disease, responding only to cyclosporin. Adv Exp Med Biol 2003;528:337-8.

Copyright 2019 BMJ Publishing Group. All rights reserved. For permission to reuse any of this content visit

https://www.bmj.com/company/products-services/rights-and-licensing/permissions/

BMJ Case Report Fellows may re-use this article for personal use and teaching without any further permission.

Become a Fellow of BMJ Case Reports today and you can:

- Submit as many cases as you like

- Enjoy fast sympathetic peer review and rapid publication of accepted articles

- Access all the published articles

Re-use any of the published material for personal use and teaching without further permission

Customer Service

If you have any further queries about your subscription, please contact our customer services team on +44 (0) 2071111105 or via email at support@bmj.com.

Visit casereports.bmj.com for more articles like this and to become a Fellow 